\title{
What is the empirical basis for converting banded ordinal data on numbers of sex partners among MSM into a continuous scale level variable? A secondary analysis of 13 surveys across 17 countries
}

Ana Mendez-Lopez ${ }^{1}$, Ford Hickson? ${ }^{2}$, Klaus Jansen ${ }^{3}$, Nathan Lachowsky ${ }^{4,5}$, Fiona Burns ${ }^{6}$, Cinta Folch ${ }^{7}$, Annie Velter ${ }^{8}$, Peter Weatherburn $^{2}$, Ulrich Marcus ${ }^{3 *}$, Ursula von Rüden ${ }^{9}$, Massimo Mirandola10,11, Lorenzo Gios ${ }^{10,11}$, Jamie Frankis ${ }^{12}$, David J. Brennan ${ }^{13}$ and Axel J. Schmidt ${ }^{2^{*}}$

\begin{abstract}
Background: To provide empirically based guidance for substituting partner number categories in large MSM surveys with mean numbers of sexual and condomless anal intercourse (CAI) partners in a secondary analysis of survey data.

Methods: We collated data on numbers of sexual and CAl partners reported in a continuous scale (write-in number) in thirteen MSM surveys on sexual health and behaviour across 17 countries. Pooled descriptive statistics for the number of sexual and CAl partners during the last twelve $(N=55,180)$ and 6 months $(N=31,759)$ were calculated for two sets of categories commonly used in reporting numbers of sexual partners in sexual behaviour surveys.

Results: The pooled mean number of partners in the previous 12 months for the total sample was 15.8 partners $(\mathrm{SD}=36.6)$, while the median number of partners was $5(\mathrm{IQR}=2-15)$. Means for number of partners in the previous 12 months for the first set of categories were: 16.4 for $11-20$ partners $(S D=3.3)$; 27.8 for $21-30(S D=2.8) ; 38.6$ for 31-40 (SD = 2.4); 49.6 for 41-50 (SD = 1.5); and 128.2 for 'more than 50' (SD=98.1). Alternative upper cut-offs: 43.4 for 'more than 10' $(S D=57.7) ; 65.3$ for 'more than 20 ' $(S D=70.3)$. Self-reported partner numbers for both time frames consistently exceeded 200 or 300 . While there was substantial variation of overall means across surveys, the means for all chosen categories were very similar. Partner numbers above nine mainly clustered at multiples of tens, regardless of the selected time frame. The overall means for CAI partners were lower than those for sexual partners; however, such difference was completely absent from all categories beyond ten sexual and CAI partners.
\end{abstract}

\footnotetext{
*Correspondence: marcusu@rki.de; axel.j.schmidt@emis-project.eu

2 Sigma Research, Department of Public Health, Environments

and Society, London School of Hygiene \& Tropical Medicine, 15-17

Tavistock Place, London WC1H 9SH, UK

${ }^{3}$ Department for Infectious Disease Epidemiology, Robert Koch Institute

Berlin, Germany

Full list of author information is available at the end of the article
}

(C) The Author(s) 2022. Open Access This article is licensed under a Creative Commons Attribution 4.0 International License, which permits use, sharing, adaptation, distribution and reproduction in any medium or format, as long as you give appropriate credit to the original author(s) and the source, provide a link to the Creative Commons licence, and indicate if changes were made. The images or other third party material in this article are included in the article's Creative Commons licence, unless indicated otherwise in a credit line to the material. If material is not included in the article's Creative Commons licence and your intended use is not permitted by statutory regulation or exceeds the permitted use, you will need to obtain permission directly from the copyright holder. To view a copy of this licence, visit http://creativecommons.org/licenses/by/4.0/. The Creative Commons Public Domain Dedication waiver (http://creativeco mmons.org/publicdomain/zero/1.0/) applies to the data made available in this article, unless otherwise stated in a credit line to the data. 
Conclusions: Clustering of reported partner numbers confirm common MSM sexual behaviour surveys' questionnaire piloting feedback indicating that responses to numbers of sexual partners beyond 10 are best guesses rather than precise counts, but large partner numbers above typical upper cut-offs are common.

Keywords: Sexual behaviour, Men-who-have-sex-with-men, Survey research

\section{Background}

Survey designers and statisticians often have distinct needs when it comes to the choice of ordinal or continuous scale level variables for measuring sexual behaviours, for example, numbers of sexual or condomless anal intercourse (CAI) partners.

In sexual behaviour surveys with men who have sex with men (MSM), piloting survey questions on partner numbers has shown that men struggle with reporting precise partner numbers when they had ten or more partners in the past six or twelve months [1,2]. Instead, respondents provide rounded estimates rather than precise counts when reporting numbers of partners beyond nine. For this reason, many surveys today use a mixture of continuous and ordinal scales, starting with a continuous scale format for partner numbers between 0 and 9 (or 10 , or 19, or 20), and switching to categories thereafter.

For example, the European MSM Internet Survey (EMIS), the largest survey on sexual behaviour and sexual health among MSM worldwide, used the following answer format: $0,1,2,3,4,5,6,7,8,9,10,11-20,21-30$, 31-40, 41-50, more than 50 for reporting sexual partner numbers [1]. However, statisticians often prefer calculating the attributable risk for each additional partner, for which a continuous scale variable is needed. The last category, be it 'more than 10', 'more than 20', or 'more than 50 ' is particularly difficult as the average number beyond this cut-off is unknown.

The aim of this study is to explore the clustering of reported numbers of sexual partners in studies with an open answer format, and to provide an empirical basis for substituting categories of partner numbers with their probable mean. This exercise allows us to explore the validity of alternative designs of survey questions and potential sources of bias in questionnaire design and respondents' reporting in sexual behaviour surveys, providing methodological insights in sexual behaviour research.

\section{Methods}

\section{Data sources}

We collated data on number of sexual partners reported in a continuous scale in MSM surveys on sexual health and behaviour. We contacted epidemiologists and social researchers from the EMIS network [1-3] across Europe and Canada (typically at least one academic and/or governmental partner per country) to identify behavioural surveys among MSM conducted in their respective countries, and asked them which of the national surveys had used open write-in fields for the numbers of sexual partners. Thirteen national and multi-national surveys were identified as eligible, and data of the partner number write-in fields were obtained from these surveys and included in our analyses [4-15]. The surveys were undertaken between 1995 and 2019 across Europe and in Canada.

All surveys asked about the overall number of sexual partners, with four also asking specifically about the number of CAI partners. Eight surveys provided data for numbers of sexual partners over the previous 12 months and five for over the previous 6 months. Table 1 (header) lists all the surveys included, years and countries in which they were performed, type of data collected, and time frame (recall period).

\section{Statistical analyses}

Pooled descriptive statistics for the number of sexual partners over the previous 12 months were calculated, first, for the total number of survey respondents and, second, for two sets of commonly used categories for reporting number of sexual partners in sexual behaviour surveys. The first commonly used set of categories included the following bands: $11-20 ; 21-30 ; 31-40 ; 41-50$; more than 50 partners (and more than 10; more than 20 as alternative upper cut-offs). The second set included 10-19; 20-29; $30-39 ; 40-49 ; 50$ or more partners (and 10 or more; 20 or more as alternative upper cut-offs). These are two separate sets of categories with different cut-offs in their bands, thus providing different ranges (e.g., in the first set there is the category 10-19 sexual partners and in the second set there is the category 11-20 sexual partners).

Next, we calculated the mean number of sexual partners by time frame (over the previous 12 months vs. the previous 6 months), by survey (for each of the thirteen included surveys), and by type of sexual partner (any sexual partner vs. CAI partners) for one of the commonly reported set of categories to assess potential differences in the means by each of these aspects and to contrast the robustness of the first findings.

Respondents reporting 'zero' partners were excluded from the overall $\mathrm{N}$ and, thus, from the overall mean and all sample share proportions. Respondents with missing data on partner numbers were also excluded. 


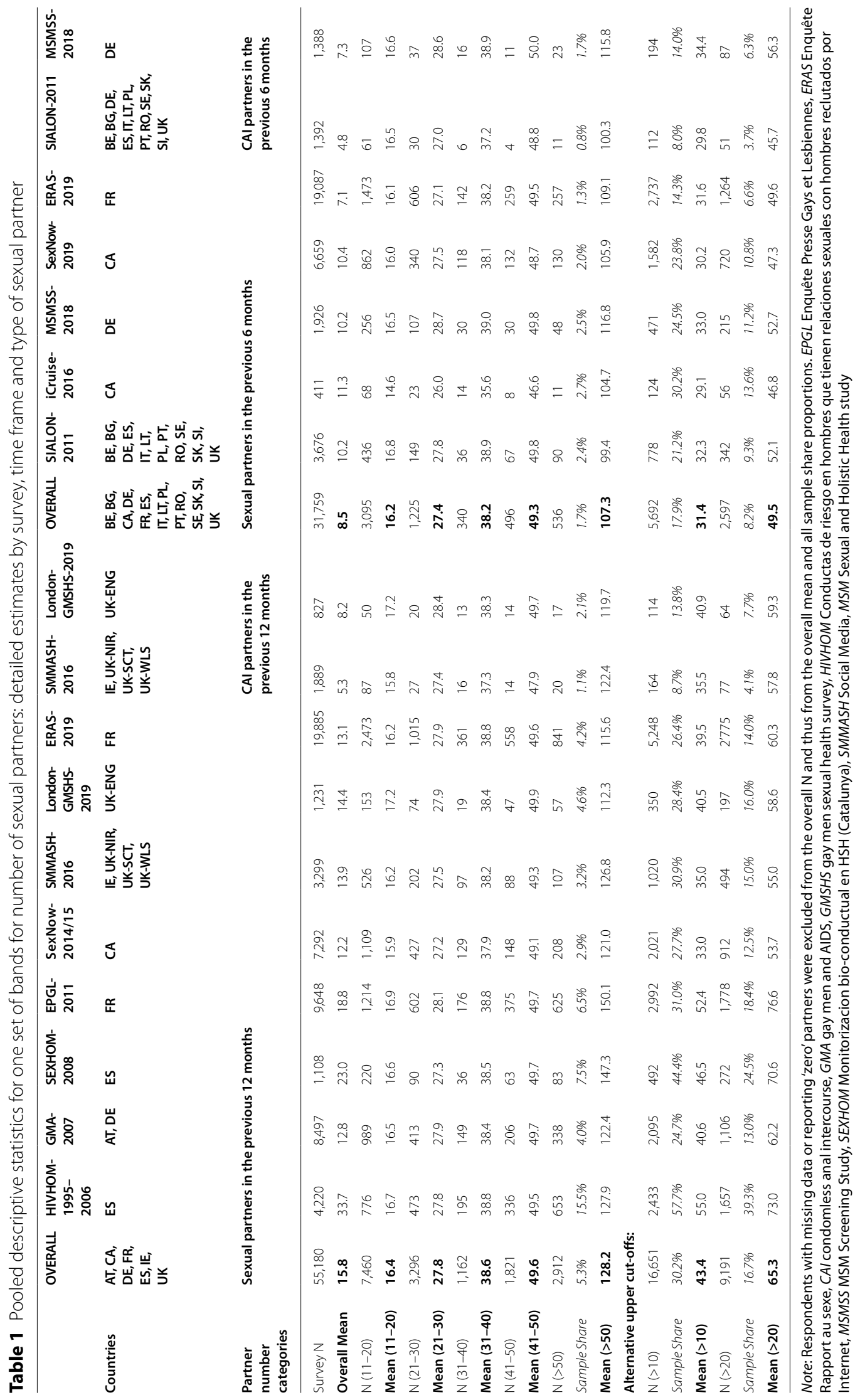




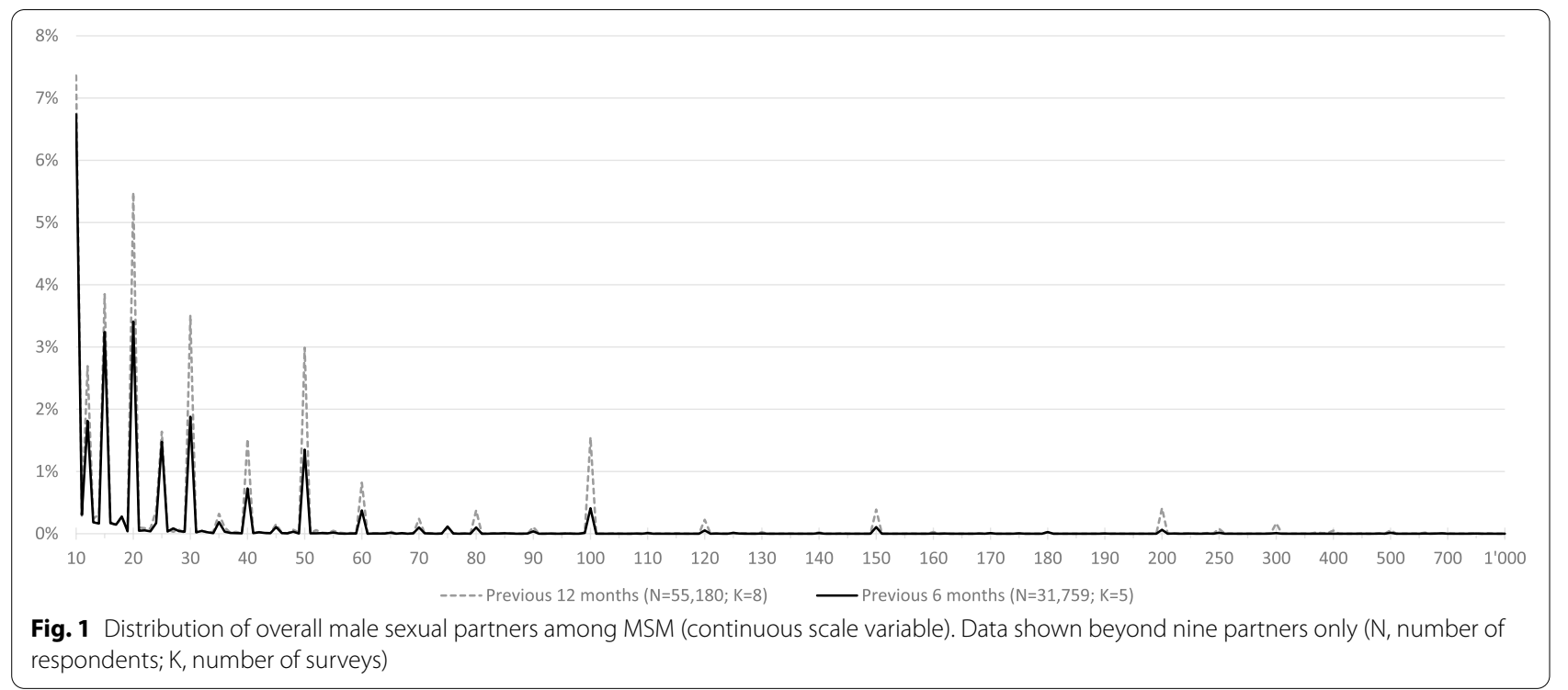

The write-in answer '999' $(N=29)$, which may have represented the researcher code 'missing', and the answers '1000' and '2000' $(N=11)$, which were extreme outliers, were excluded.

\section{Results}

Across all surveys, the combined sample size of respondents reporting the number of sexual partners in the previous 12 and previous 6 months was 55,180 and 31,759, respectively.

Figure 1 depicts the distribution of overall male sexual partners among MSM reporting more than nine partners. Across all surveys, the number of partners had an asymmetrical distribution skewed to the right. Self-reported partner numbers for both time frames consistently exceeded 200 or 300 . Partner numbers beyond nine mainly clustered at 10, 12, 15, 20, 25, 30, 40, 50, 60, 80, 100, 120, 150,200 , and 300 , regardless of the selected time frame.

Table 2 shows the total number and proportion of respondents reporting partners in each category, and pooled descriptive statistics (mean, standard deviation, median, and interquartile range) for each of the two alternative sets of bands. The pooled mean number of partners in the previous 12 months for the total sample was 15.8 partners $(\mathrm{SD}=36.6)$, while the median number of partners was $5(I Q R=2-15)$. Means for number of partners in the previous 12 months for the first set of categories were: $\mathbf{1 6 . 4}$ for $11-20$ partners $(S D=3.3)$; 27.8 for $21-30(\mathrm{SD}=2.8)$; $\mathbf{3 8 . 6}$ for $31-40(\mathrm{SD}=2.4)$; 49.6 for $41-50(\mathrm{SD}=1.5)$; and $\mathbf{1 2 8 . 2}$ for 'more than 50 ' $(\mathrm{SD}=98.1)$. For the alternative upper cut-offs, mean partner numbers were $\mathbf{4 3 . 4}$ for 'more than 10 ' $(\mathrm{SD}=57.7)$, and $\mathbf{6 5 . 3}$ for 'more than 20' $(\mathrm{SD}=70.3)$.
Means for the second set of commonly reported categories were: $\mathbf{1 2 . 1}$ for $10-19$ partners $(S D=2.4)$; 21.4 for $20-29(\mathrm{SD}=2.3)$; 30.7 for $30-39(\mathrm{SD}=1.8)$; 40.9 for $40-49(\mathrm{SD}=2.2)$; and 99.9 for ' 50 or more' $(\mathrm{SD}=86.9)$. For the alternative upper cut-offs, mean partner numbers were $\mathbf{3 6 . 8}$ for ' 10 or more' $(\mathrm{SD}=53.4)$; $\mathbf{5 4 . 1}$ for '20 or more' $(\mathrm{SD}=64.1)$.

Mean number of sexual partners for the first set of categories (those whose bands commenced with a multiple of ten, e.g. 30-39) consistently resulted in a lower mean compared to the alternative band (those containing a multiple of ten in the upper end of the range, e.g. 31-40). According to the right skewed distribution (Fig. 1), all reported medians are consistently lower than the reported means (Table 2).

Table 1 shows, for each survey considered, the numbers and proportions of respondents reporting partners in each category, and the mean number of partners reported within each category, for both the previous 12 months and previous 6 months, and for both number of sexual partners and number of CAI partners. These data are provided only for one of the commonly used set of categories.

While there was substantial variation across all surveys with respect to the overall mean numbers, the means for all categories were very similar.

Across the two time frames, the overall mean number of sexual partners in the previous 6 months was $54 \%$ of the overall mean partner number in the previous 12 months. When moving towards higher partner number categories, this proportion increased steadily to $72 \%$ ('more than 10 '), 76\% ('more than 20'), and 84\% ('more than 50').

Irrespective of the time frame, in all surveys providing estimates for the number of sexual and CAI partners, the overall means for CAI partners were lower than those for 
Table 2 Pooled descriptive statistics for two sets of alternative bands for number of sexual partner categories: overall estimates for number of sexual partners for all the included MSM surveys

\begin{tabular}{|c|c|c|c|}
\hline \multicolumn{2}{|c|}{$\begin{array}{l}\text { Categories for numbers of sexual } \\
\text { partners: } \\
\text { EMIS categories }\end{array}$} & \multicolumn{2}{|c|}{$\begin{array}{l}\text { Categories for numbers of } \\
\text { sexual partners: } \\
\text { alternative categories }\end{array}$} \\
\hline Total & & Total & \\
\hline N (\%) & $55,180(100 \%)$ & N (\%) & $55,180(100 \%)$ \\
\hline Mean (SD) & $15.8(36.6)$ & Mean (SD) & $15.8(36.6)$ \\
\hline Median (IQR) & $5(2-15)$ & Median & $5(2-15)$ \\
\hline 11-20 partners & & 10-19 partner & \\
\hline$N(\%)$ & 7460 (13.5\%) & $N(\%)$ & 8497 (15.4\%) \\
\hline Mean (SD) & $16.4(3.3)$ & Mean (SD) & $12.1(2.4)$ \\
\hline Median (IQR) & $15(14-20)$ & Median & $12(10-15)$ \\
\hline 21-30 partners & & 20-29 partner & \\
\hline$N(\%)$ & $3296(6.0 \%)$ & $N(\%)$ & 4385 (8.0\%) \\
\hline Mean (SD) & $27.8(2.8)$ & Mean (SD) & $21.5(2.3)$ \\
\hline Median (IQR) & $30(25-30)$ & Median & $20(20-24)$ \\
\hline 31-40 partners & & 30-39 partner & \\
\hline$N(\%)$ & $1162(2.1 \%)$ & $N(\%)$ & 2259 (4.1\%) \\
\hline Mean (SD) & $38.6(2.4)$ & Mean (SD) & $30.7(1.8)$ \\
\hline Median (IQR) & $40(37-40)$ & Median & $30(30-30)$ \\
\hline 41-50 partners & & 40-49 partner & \\
\hline N (\%) & $1821(3.3 \%)$ & N (\%) & $1011(1.8 \%)$ \\
\hline Mean (SD) & $49.6(1.5)$ & Mean (SD) & $40.9(2.2)$ \\
\hline Median (IQR) & $50(50-50)$ & Median (IQR) & $40(40-40)$ \\
\hline$>50$ partners & & $\geq 50$ partners & \\
\hline N (\%) & 2912 (5.3\%) & $N(\%)$ & 4561 (8.3\%) \\
\hline Mean (SD) & $128.2(98.1)$ & Mean (SD) & $99.9(86.9)$ \\
\hline Median (IQR) & $100(75-150)$ & Median (IQR) & $70(50-100)$ \\
\hline \multicolumn{4}{|c|}{ Alternative upper cut-offs } \\
\hline$>20$ partners & & $\geq 20$ partners & \\
\hline$N(\%)$ & $9191(16.7 \%)$ & $\mathrm{N}(\%)$ & $12,216(22.1 \%)$ \\
\hline Mean (SD) & $65.3(70.3)$ & Mean (SD) & $54.1(64.1)$ \\
\hline Median (IQR) & $48(30-70)$ & Median (IQR) & $30(21-50)$ \\
\hline$>10$ partners & & $\geq 10$ partners & \\
\hline$N(\%)$ & $16,651(30.2 \%)$ & $N(\%)$ & $20,713(37.5 \%)$ \\
\hline Mean (SD) & $43.4(57.7)$ & Mean (SD) & $36.8(53.4)$ \\
\hline Median (IQR) & $25(16-50)$ & Median (IQR) & $20(12-40)$ \\
\hline
\end{tabular}

Notes: SD Standard Deviation, IQR Inter-quartile Range

sexual partners. Such difference was absent from all categories beyond ten sexual and CAI partners.

\section{Discussion}

Using data from thirteen national and multi-national sexual behaviour surveys among MSM, we looked at the distribution of partner numbers in the previous 12 and 6 months and calculated means for two commonly used sets of partner number categories.
The means and medians for the two sets of commonly reported categories show very different results because of clustering of responses in the tens, which pulled down, or up, the mean and medians toward the tens, whether it was included in the upper or lower limit of the band range. Clustering of reported partner numbers confirm MSM sexual behaviour surveys' questionnaire piloting feedback, such as that from the EMIS $[1,2]$, that partner numbers beyond nine-and irrespective of the chosen time frame-were best guesses rather than precise counts, with 'twelve', ' 60 ', and ' 120 ' possibly reflecting 'about one per month', 'about five per month', and 'about ten per month', respectively, in a 12 months retrospective period.

The decreasing difference between means of partner numbers in higher categories across the two time frames may be due to the so-called telescoping effect, a cognitive effect in survey research, whereby there is a temporal displacement of events [16]. In this case events may be perceived as having happened some time nearer or further from the time of interview. This consistently occurred across all included surveys, and this effect may have slightly inflated the reported number of partners in the higher categories of surveys querying about the previous 6 months.

Above nine partners, the mean numbers of sexual and CAI partners were rather similar, suggesting that noncondom use is intermittent during anal sex with a smaller number of partners, but may become more common when dealing with larger numbers of sexual (intercourse) partners.

We found that for the higher categories in both sets of bands, i.e. 'more than 50' / '50 or more', the associated interquartile ranges were wide and the standard deviations were high in relation to the means (Table 2). Given the large dispersion of the distribution in the highest categories of both sets of bands, adding an additional category in the upper range of the sets (for example, a category measuring 51-100 / 50-99 sexual partners and an additional capturing 'more than 100 ' / '100 or more' sexual partners), may provide greater precision in measurement in surveys collecting data with categorical variables. Greater accuracy in the estimation of the number of sexual partners in the MSM population may contribute to overcoming difficulties in the prevention and control of the HIV/STI epidemics and their risk assessment.

One limitation of this analysis is that our findings may not transfer to MSM behaviour in other countries outside the regions of the countries from the surveys, especially those countries where homosexuality is highly stigmatised. Another limitation is that our selection of MSM surveys was not strictly systematic, however, given the composition of the research network, we consider 
it unlikely that we missed large European or Canadian surveys that no-one in the network was aware of. Additionally, the time lapse between the earliest and latest surveys is of almost 25 years, a time period throughout which MSM sexual behaviour may have changed due to, for instance, developments in HIV/STI interventions or cultural changes related to reduced stigmatization. Nonetheless, we do not expect the potential omission of a survey or the time lapse between the included surveys to have substantially impacted on the overall results. The large number of surveys included makes our study a comprehensive review and summary of the sexual behaviour in terms of number of sexual partners of MSM in Canada and Europe.

\section{Conclusions}

The variations of the calculated means across surveys conducted in different countries, study populations and years were low. Therefore, we believe that the results can serve to foster methodologically robust substitution of partner number categories with probable mean numbers of sexual and CAI partners in MSM-oriented surveys.

\section{Abbreviations}

CAI: Condomless anal intercourse; EMIS: European MSM Internet Survey; MSM: Men-who-have-sex-with-men.

\section{Acknowledgements}

Dr. Michael Bochow, Berlin, Germany, initiated the German GMA surveys. Stop sida, Barcelona, Spain, partner NGO of HIVHOM and SEXHOM surveys. Community Based Research Centre in Vancouver, Canada, ran the Sex Now surveys.

\section{Authors' contributions}

AJS and UM conceptualised the analysis, AJS reached out to partners, compiled the data, calculated the numbers, and drafted the manuscript. AML reviewed the statistics, finalised the manuscript and the tables, and wrote the abstract. All authors reviewed and contributed to the manuscript. AJS, FH, PW, UM et al. conducted EMIS-2010 and 2017; AJS, UR et al. conducted GMA-2007; KJ et al. conducted MSMSS-2018; NL et al. conducted SexNow-2014/15/19; FB et al. conducted London-GMSHS-2019; CF et al. conducted HIVHOM-1995-2006 and SEXHOM-2008; AV et al. conducted EPGL2011 and ERAS-2019; MM, LG, CF, UM et al. conducted SIALON-2011; JF et al. conducted SMMASH-2016, DJB et al. conducted iCruise-2016. All authors have read and approved the manuscript.

\section{Funding}

- Open Access funding enabled and organized by Projekt DEAL.

- The Sex Now Survey 2015 was possible thanks to a grant from the Vancouver Foundation.

- The Sex Now 2019 research received funding support from Canadian Blood Services MSM Research Fund, funded by the federal government (Health Canada) and the provincial and territorial ministries of health. The views herein do not necessarily reflect the views of Canadian Blood Services or the federal, provincial, or territorial governments of Canada. NJL was supported by a Scholar Award from the Michael Smith Foundation for Health Research (\#16863).

- The \#iCruise survey was funded by the Canadian Foundation for AIDS Research and the Canadian Institutes for Health Research. DJB was supported by an Endgame Leadership Chair Award from the Ontario HIV Treatment Network.

- Both, EPLG2011 and Rapport au sexe 2019 were supported by the National Agency for Research on AIDS and Viral Hepatitis (ANRS).
- HIVHOM-1995-2006 and SEXHOM-2008 were supported by the Department of Health, Generalitat de Catalunya; Agència de Gestió d'Ajuts Universitaris i de Recerca - AGAUR (2005/SGR/00505), Departament d'Universitats, Recerca i Societat de la Informació, de la Generalitat de Catalunya; and Centro de Investigación Biomédica en Red (CIBER) - CIBER de Epidemiología y Salud Pública (CIBERESP).

- SMMASH-2016 was partly funded from a grant from NHS Greater Glasgow and Clyde and NHS Lothian, UK. JF is funded by Glasgow Caledonian University.

- London GMSHS 2019 was funded by the Terrence Higgins Trust, National Institute for Health Research Health Protection Research Unit (NIHR HPRU) in Blood Borne and Sexually Transmitted Infections at University College London in partnership with Public Health, England (PHE), The views expressed are those of the authors and not necessarily those of the NIHR, the Department of Health and Social Care Public Health England, or the Terrence Higgins Trust.

- Part of the data used for this manuscript is based on the Sialon II project data, co-funded under the Second Programme of Community Action in the field of Health (2008-2013) (Work Plan 2010).

- The German 2007 survey 'Gay men and AIDS' was funded by the Federal Centre for Health Education (BZgA). The BZgA is a specialist authority within the portfolio of the Federal Ministry of Health.

\section{Availability of data and materials}

The datasets used and/or analysed during the current study are available from the corresponding author on reasonable request.

\section{Declarations}

Ethics approval and consent to participate

Not applicable.

\section{Consent for publication}

Not applicable.

\section{Competing interests}

The authors declare that they have no competing interests.

\section{Author details}

${ }^{1}$ Department of Preventive Medicine, Public Health and Microbiology, School of Medicine, Autonomous University of Madrid, Madrid, Spain. ${ }^{2}$ Sigma Research, Department of Public Health, Environments and Society, London School of Hygiene \& Tropical Medicine, 15-17 Tavistock Place, London WC1H 9SH, UK. ${ }^{3}$ Department for Infectious Disease Epidemiology, Robert Koch Institute, Berlin, Germany. ${ }^{4}$ School of Public Health and Social Policy, University of Victoria, Victoria, Canada. ${ }^{5}$ Community Based Research Centre, Vancouver, Canada. ${ }^{6}$ Institute for Global Health, University College London, London, UK. ${ }^{7}$ Centre d'Estudis Epidemiològics sobre les Infeccions de Transmissió Sexual i Sida de Catalunya (CEEISCAT), Agència de Salut Pública de Catalunya, Barcelona, Spain; CIBER Epidemiologia y Salud Pública (CIBERESP), Instituto de Salud Carlos III, Madrid, Spain. ${ }^{8}$ Direction Prévention, Promotion de la santé, Agence nationale de santé publique, Saint Maurice, France. ${ }^{9}$ Bundeszentrale für Gesundheitliche Aufklärung, Cologne, Germany. ${ }^{10}$ Infectious Diseases Section, Department of Diagnostics and Public Health, University of Verona, Verona, Italy. ${ }^{11}$ School of Health Sciences, University of Brighton, Brighton, UK. ${ }^{12}$ School of Health and Life Sciences, Glasgow Caledonian University, Glasgow, UK. ${ }^{13}$ Factor-Inwentash Faculty of Social Work, University of Toronto, Toronto, Canada.

Received: 28 June 2021 Accepted: 5 October 2021

Published online: 06 March 2022

\section{References}

1. Weatherburn P, Hickson F, Reid DS, Marcus U, Schmidt AJ. European men-who-have-sex-with-men internet survey (EMIS-2017): design and methods. Sex Res Soc Policy. 2020;17:543-57. https://doi.org/10.1007/ s13178-019-00413-0.

2. Weatherburn P, Schmidt AJ, Hickson F, Reid D, Berg RC, Hospers HJ, et al. The European men-who-have-sex-with-men internet survey (EMIS): design and methods. Sex Res Soc Policy. 2013;10(4):243-57. 
3. EMIS network. European Men-who-have-sex-with-men Internet Suvey 2017 website. 2017 [Available from: www.emis2017.eu].

4. Folch C, Muñoz R, Zaragoza K, Casabona J. Sexual risk behaviour and its determinants among men who have sex with men in Catalonia, Spain. Eurosurveillance. 2009;14(47):19415.

5. Méthy N, Velter A, Semaille C, Bajos N. Sexual behaviours of homosexual and bisexual men in France: a generational approach. PLoS One. 2015;10(3):e0123151-e.

6. Gios L, Mirandola M, Toskin I, Marcus U, Dudareva-Vizule S, Sherriff N, et al. Bio-behavioural HIV and STI surveillance among men who have sex with men in Europe: the Sialon II protocols. BMC Public Health. 2016;16(1):212.

7. Frankis J, Flowers P, McDaid L, Bourne A. Low levels of chemsex among men who have sex with men, but high levels of risk among men who engage in chemsex: analysis of a cross-sectional online survey across four countries. Sex Health. 2018;15(2):144-50.

8. Logan L, Fakoya I, Howarth A, Murphy G, Johnson AM, Rodger AJ, et al. Combination prevention and HIV: a cross-sectional community survey of gay and bisexual men in London, October to December 2016. Euro Surveill. 2019;24(25):1800312.

9. Card KG, Fournier AB, Sorge JT, Morgan J, Grace D, Ham D, et al. Substance use patterns and awareness of biomedical HIV prevention strategies among sexual and gender minority men in Canada. AIDS Care. 2020;32(12):1506-14.

10. Jansen K, Steffen G, Potthoff A, Schuppe A-K, Beer D, Jessen H, et al. STI in times of PrEP: high prevalence of chlamydia, gonorrhea, and mycoplasma at different anatomic sites in men who have sex with men in Germany. BMC Infect Dis. 2020;20(1):110.

11. Duchesne L, Lydié N, Velter A. Increase in the overall level of protected anal sex in men who have sex with men in France: results from the repeated cross-sectional survey rapport au Sexe, France, 2017-2019. AIDS Care. 2020;32(sup2):162-9.

12. Brennan DJ, Kesler M, Lachowsky NJ, Davies A, Georgievski G, Adam BD, et al. Sociodemographic and Psychological Predictors of Seeking Health Information Online among GB2M in Ontario: Findings from the \#iCruise Project, International Journal of Sexual Health. 2021. https://doi.org/10. 1080/19317611.2021.2000087.

13. Bochow M, Schmidt AJ, Grote S. Schwule Männer und HIV/AIDS: Lebensstile, Szene, Sex 2007. Ein Befragung im Auftrag der Bundeszentrale für gesundheitliche Aufklärung, Köln. Belin: AIDS-Forum DAH; 2010.

14. Centre d'Estudis Epidemiològics sobre la Sida de Catalunya (CEESCAT). Informe epidemiològic biennal CEEISCAT. Sistema integrat de vigilància epidemiològica de la SIDA/VIH/ITS a Catalunya. SIVES 2010. Barcelona: Generalitat de Catalunya, Departament de Salut; 2011.

15. Ferlatte O, Salway T, Trussler T, Oliffe JL, Gilbert M. Combining intersectionality and syndemic theory to advance understandings of health inequities among Canadian gay, bisexual and other men who have sex with men. Crit Public Health. 2018;28(5):509-21.

16. Kupek E. Bias and heteroscedastic memory error in self-reported health behavior: an investigation using covariance structure analysis. BMC Med Res Methodol. 2002;2(1):14.

\section{Publisher's Note}

Springer Nature remains neutral with regard to jurisdictional claims in published maps and institutional affiliations.

Ready to submit your research? Choose BMC and benefit from:

- fast, convenient online submission

- thorough peer review by experienced researchers in your field

- rapid publication on acceptance

- support for research data, including large and complex data types

- gold Open Access which fosters wider collaboration and increased citations

- maximum visibility for your research: over 100M website views per year

At BMC, research is always in progress.

Learn more biomedcentral.com/submissions 